24. Palmer CG, Schwartz S, Hodes ME. Transmission of a balanced homologous $t(22 q$; 22q) translocation from mother to normal daughter. Clin Genet 1980; $17: 418$

25. Bishun NP, Morton WRM. Chromosome studies on women who have had two or more unsuccessful pregnancies. J Obstet Gynaecol Brit Cwlth 1968; $75: 66$

26. Singh DN, Hara S, Foster HW, Grimes EM. Reproductive performance in women with sex chromosome mosaicism. Obstet Gynecol $1980 ; 55: 608$

27. Stoll C. Cytogenetic findings in 122 couples with recurrent abortions. Hum Genet 1981: $57: 101$

28. Hecht $F$. Unexpected encounters in cytogenetics : Repeated abortions and parental sex chromosome mosaicism may indicate risk of non-disjunction. Amer $\mathbf{J}$ Hum Genet 1982; $34: 514$
29. Dewhurst J. Fertility in $47, \mathrm{XXX}$ and 45 , $X$ patients. J Med Genet 1978; 15 : 132

30. Khudı G. Cytogenetics of habitual abortion. A review. Obstet Gynec Surr 1974; 29 : 299

31. Abuelo DN, Barsel-Bowers G. Prognosis for couples who have experienced repeated pregnancy loss. Fertil Steril $1983 ; 40: 844$

32. Uchida IA, Freeman VCP. Trisomy 21 Down syndrome: Parental mosaicism. Hum Genet 1985; $70: 246$

33 Hsu LYF, Gertner M, Leiter E, Hirschhorn K. Parental trisomy 21 mosaicism and Down's syndrome. Amer J Hum Genet 1971; 23 : 592

34. Harris DJ, Begleiter ML, Chamberlin $J$, Hankins, L, Magenis RE. Parental trisomy 21 mosaicism. Amer J Hum Genet 1982: 34 : 125

35. Wentz AC, Wilroy RS, Marten PR. Luteal phase inadequacy and a chromosomal anomaly in recurrent abortions. Fertil Steril 1984: $41: 142$

\title{
FETO-PLACENTAL STEROID METABOLISM IN GROWTH RETARDED HUMAN FETUSES
}

Women bearing fetuses with intrauterine growth retardation (IUGR) frequently have low serum estriol (E3) levels in the gestation. One origin of the low $\mathrm{E}_{3}$ production in these pregnancies may be reduced secretion of fetal adrenal cortex-derived neutral steroid precursors of estriol synthesis in the placenta. However, there is evidence that placental conversion of the neutral precursors to estrogen may be low in association with a fetus with IUGR. In order to investigate the relative importance of these two possible causes of low $E_{3}$ production, umbilical venous, and maternal venous neutral steroid and estrogen levels were assessed in a series of pregnancies in which the fetus had IUGR.

The significantly low $\mathrm{E}_{3}$ values in both umbilical and maternal samples are postulated to result not only from the reduced fetal adrenal dehydroepiandrosterone sulfate (DHAS) secretion, but also underactive $16 x$-hydroxylase activity in fetal liver or low efficiency of $16 \alpha-\mathrm{OH}-\mathrm{DHAS}$ relative to DHAS, as a substrate for placental conversion to an estrogen. 